\title{
Functional difficulties and toileting among older adults in Ghana: evidence from the World Health Organization Study on global AGEing and adult health (SAGE) Ghana Wave 1
}

\author{
Kofi Awuviry-Newton ${ }^{1 \star}$ (D), Kylie Wales ${ }^{1,2}$ (D), Meredith Tavener ${ }^{1}$, Paul Kowal ${ }^{1}$ and Julie Byles ${ }^{1}$ \\ ${ }^{1}$ Priority Research Centre for Generational Health and Ageing, Faculty of Health and Medicine, \\ Department of Public Health and Medicine, University of Newcastle, Newcastle, New South Wales, \\ Australia and ${ }^{2}$ School of Health Sciences, University of Newcastle, Newcastle, New South Wales, Australia \\ ${ }^{\star}$ Corresponding author. Email: newscous@gmail.com
}

(Accepted 2 March 2021; first published online 12 April 2021)

\begin{abstract}
Ghana's older population is projected to increase in coming decades and as a result will see increasing care needs. Understanding the functional difficulties older adults experience, and the associated factors, will help identify relevant intervention to assist older adults in meeting their care needs. This study aimed to analyse the prevalence of functional difficulties among older adults in Ghana, and examine how the World Health Organization International Classification of Functioning, Disability and Health (WHO-ICF) conceptual framework can relate to toileting difficulty to understand the factors that increase older adults' care needs. Data were for 5,096 adults aged $\geqslant 50$ years from the WHO Study on global AGEing and adult health (SAGE) Ghana Wave 1. Difficulties were assessed using selfreported difficulty on 22 functional items, including toileting. Multivariate logistic regression tested associations between toileting and other factors as related to the WHO-ICF conceptual framework. Older adults reported climbing one flight of stairs without resting as a common functional difficulty. Difficulty eating was the item least identified. Toileting difficulty was ranked second among five total activities of daily living difficulties. Age, marital status, self-reported health, memory, bodily pain, short- and far-distance vision, obesity, stroke, chronic lung disease, trust at individual and neighbourhood level, toilet facility type, socialising with co-workers, and public and religious meeting attendance were statistically significantly associated with toileting difficulty in the final parsimonious model. Post-hoc analysis testing interaction revealed that interaction existed between female sex and never married marital status $(p=0.04)$, and obesity and widowed marital status $(p=0.01)$, with toileting as the outcome. A significant level of functional difficulty existed among Ghanaian older adults in this sample. Toileting difficulty was associated with factors across different components in the WHO-ICF, emphasising functional, social and environmental factors related to this fundamental human activity.
\end{abstract}

(C) The Author(s), 2021. Published by Cambridge University Press. This is an Open Access article, distributed under the terms of the Creative Commons Attribution licence (http://creativecommons.org/licenses/by/4.0/), which permits unrestricted re-use, distribution, and reproduction in any medium, provided the original work is properly cited. 
Keywords: functional difficulty; Ghana; older adults; toileting difficulty; World Health Organization International Classification of Functioning; Disability and Health (WHO-ICF)

\section{Introduction}

The older population in Ghana is growing rapidly in number, due to decreasing birth rates and delayed mortality (Biritwum et al., 2013a). Ghana's birth rates have steadily decreased from 6.7 births per woman in 1960 to 4.2 in 2015 with a further decline to 2.7 births predicted by 2050 (United Nations, 2017). The projected reduction will be higher than the anticipated decline in birth rates in highincome countries (Orji et al., 2017). Life expectancy at birth of 46.9 (1960) was 63.7 in 2020 with a further increase to approximately 70 years by 2050 and 76.2 by 2100 (United Nations Department of Economic and Social Affairs, Population Division, 2019). Ghana's older population (defined here as people aged 60 years or older) (Ghana Statistical Service, 2013) increased from 273,400 (4.1\%) to 1.69 million (5.5\%) in the 60 years between 1960 and 2020. The pace of ageing is set to increase dramatically, with the percentage of older adults projected to reach 9.8 per cent by 2050 (United Nations, 2017). A key policy issue is whether Ghana is ready to harness the opportunities, such as taking leadership roles in business and communities, that arise from population ageing and leverage the benefits of a demographic dividend (Darkwa, 2000; Butler et al., 2008; Ocansey et al., 2013; Bloom and Luca, 2016).

One of the challenges associated with population ageing is the increased need for care and whether policy and programmes adequately address these needs (Debpuur et al., 2010; Awuviry-Newton et al., 2020a, 2020b, 2020c; Nkansah et al., 2021). To develop policies and programmes that are suitable for an ageing population, we must first seek to understand older adults' care needs in terms of their functional difficulties. Many cross-sectional studies have examined functional difficulties among older adults, particularly in higher-income countries. However, there has been less research into functional difficulties among older adults in low- and middle-income countries (LMIC), and very little research into functional difficulties among older adults in Africa (United Nations Department of Economic and Social Affairs, Population Division, 2015). The WHO Study on global AGEing and adult health (SAGE) project was designed to address this lack of information on ageing in LMIC (Kowal et al., 2012). One analysis from this study compared functional difficulty scores across the six SAGE countries (Ghana, Mexico, South Africa, Russian Federation, India and China) (Biritwum et al., 2016). Across all countries, functional difficulty scores were higher for women and increased with age. Age-specific scores were lowest in China, indicating less difficulty among older adults in this setting, and highest in India, with South Africa and Ghana having the next highest scores. Very few people in Ghana (less than 10\%) had no functional difficulty across items assessing cognition, mobility, self-care, getting along, life activities and participation in society (Biritwum et al., 2016). While SAGE Wave 1 results indicated that there are high levels of functional difficulty among older adults in Ghana, societal and services response to this need may require a more detailed unpacking of the nature of this difficulty, the functional dynamics, and understand the needs for specific forms of assistance and care. 
Among the functional difficulties that older adults may experience, available research indicates that toileting difficulty can be most problematic (Yeung et al., 2019). Toileting difficulty has the potential to increase the requirement for assistance, can lead to loss of independence, and can create care-giving and cost-related burdens (Schulz et al., 1987; Jones, 2009; Yeung et al., 2019). In Ghana, toileting difficulty has been reported as a dominant factor necessitating the care needs of older adults. According to Van der Geest (2002), older adults feel comfortable when they find it easy to access the toilet facilities and to ease themselves freely. According to Katz et al. (1970), toileting refers to the bowel and bladder roles, including moving to the 'toilet room' or facility, transferring on and off the toilet, cleaning after completion and arranging clothes. This definition was adopted in this current study, in that we assumed that older adults who perform the toileting activities generally undertake all activities specified by Katz et al. (1970).

In Ghana, most people depend upon public toilet facilities, located outside individual homes, for easing themselves. High rates of poverty in most households make it challenging to establish private toilet facilities (Katz et al., 1970; Songsore and McGranahan, 1993; Osumanu, 2007). Those who cannot pay or cannot walk to the public toilet use the bush or beach for their toilet place. For instance, a study conducted on the inhabitants of Wa Municipal Assembly in Ghana reports that 8.3 per cent of households in Wa have toilet facilities in their homes, 44.5 per cent use public toilets and 37.2 per cent use open defecation around river bodies (Wa Municipal Assembly, 2011). The nature of public toilets is the squat and manhole type, and the use of pit latrines with palm branches providing partitions and privacy (Quansah, 2010), which requires additional energy expenditure to move aside before toileting. These public squat and manhole type/pit latrines are often a long distance from residents' homes and are not cleaned regularly (Van der Geest, 1998; Osumanu and Kosoe, 2013; Peprah et al., 2015). The environmental and societal challenges associated with toileting in Ghana, combined with the reported link to wellbeing, highlight the need to understand further how toileting influences one's function and thus overall health.

Globally, studies exist on associated factors of overall functional difficulties rather than examining specific functional deficits (Yeung et al., 2019). Factors associated with the overall functional difficulties are often personal, health and environmentally related ( $\mathrm{Yu}$ et al., 2015; Biritwum et al., 2016; Silva et al., 2019). Perhaps the limited amount of research on a single activity of daily living (ADL) variable such as toileting may be attributed to bias in research funding, which often demands an accumulative score of individual functioning (Morris et al., 1999). Examining factors related to functional difficulty as a whole misses the unique impact and size of the association on the specific functional difficulty, and the unique needs of people with this difficulty. Accordingly, the development of interventions to target older adults' overall functional difficulty may also fail to meet these unique needs. For instance, research indicates that the loss of individual activities has a differing impact on the overall ADLs (Morris et al., 1999). The intervention for older adults who have mobility issues may be different from older adults having toileting difficulty. This difference is because factors related to these two functional difficulties may vary in nature and impact. Moreover, older adults have dignity, and the right to social justice and health care. Therefore, a study 
that examines associated factors of specific functional difficulty, in this case, toileting difficulty, is relevant to uncover factors that might influence interventions to meet the unique care needs of older adults experiencing toileting difficulty.

In one of the few studies to explore factors associated with toileting difficulty among older adults living in a residential aged care facility (Talley et al., 2014), factors include reporting poor health, increased number of physical impairments, visual and hearing impairments, and needing assistance with bathing, dressing and transferring (Talley et al., 2014). In a longitudinal study, Grimsland et al. (2019) found dementia to be significantly associated with toileting difficulty. Some studies have suggested that health factors, including depression, stroke and heart failure (Hunskaar et al., 2000; DuBeau et al., 2010), as well as environmental factors, including residence type and accessibility of bathrooms (Talley et al., 2014), may be significantly associated with toileting difficulty. None of this research was conducted in an African context, and no previous study has employed a broader framework like the World Health Organization International Classification of Functioning, Disability and Health (WHO-ICF) to evaluate the explanatory factors of toileting difficulty, which is the most predictive of dependence among older adults.

The WHO-ICF offers a universal framework that can be used to describe and understand a person's health in terms of function and disability (McGrath et al., 2015). Function, as defined by the WHO-ICF, relates to all body functions, activities and participation, while disability encompasses impairments, activity limitations and participation restrictions (WHO, 2002). The WHO-ICF acknowledges the interaction between body structures and function and environmental factors (including social relationships) (McGrath et al., 2015). This framework is also consistent with the WHO (2015) framework for healthy ageing, which considers the dynamic interaction between the intrinsic capacity of the individual (all their physical and mental attributes) and the influence of physical and social environments that enable or limit their ability to achieve the goals they value. The care needs of older adults, with toileting difficulty, cannot be adequately understood without considering the circumstances in which older adults live, work and age, and the systems put in place to deal with the difficulty older adults experience.

Toileting difficulty, in this current study, is considered as an activity limitation within the WHO-ICF framework and is expected to be influenced by one's health condition, body function and structure, participation, and personal and environmental factors. The present study will examine toileting difficulty in the context of the components of the WHO-ICF. Understanding the relationship between toileting and the WHO-ICF will assist in determining better assessment of older adults' needs, providing a comprehensive assessment of specific deficits and, potentially, utilising toileting difficulties as a flag for further assessment and intervention. In this study, we hypothesise that the higher the needs across the components of the WHO-ICF, the higher the toileting difficulty older adults will experience.

\section{Method}

\section{Study sampling}

SAGE Wave 1 was nationally representative surveys conducted in Ghana and five other countries (China, India, Mexico, Russian Federation and South Africa) 
between 2007 and 2010. The goals of SAGE included strengthening, gathering, processing and managing data on older adults and responding to identified needs through policy, planning and research (Biritwum et al., 2013b). Out of the total sample size of 5,571 participants aged 18 years and older in the cohort, this analysis reported on 5,096 participants aged 50 years and over who provided answers to items on toileting difficulty and other functional activities. The sampling procedures, as well as the methodology employed in SAGE Wave 1, has been detailed elsewhere (Kowal et al., 2012). For this analysis, the SAGE household dataset was merged with the individual dataset to include some physical environmental factors that might influence toileting difficulty in the analysis. This data linkage was possible because individual participants in each household were selected to answer the household questionnaire (Biritwum et al., 2013b).

\section{Functional difficulties}

The difficulty in functioning was assessed using 22 items across ADLs, instrumental ADLs (IADLs), abilities, cognition and mobility using ordinal response categories (none, mild, moderate, severe, extreme) (Kowal et al., 2012). The prevalence of difficulty with functional ability items is presented by sex. The prevalence of the five ADL items (transferring, toileting, bathing, dressing, eating) from the 22 functioning items were presented separately to better target the relationship of toileting to other ADLs.

\section{Dependent variable: toileting difficulty}

Included among the functioning assessment questions was: 'In the last 30 days, how much difficulty did you have with getting to and using the toilet due to health problems, injuries, mental or emotional problems?' For this analysis, the response categories 'mild', 'moderate', 'severe' and 'extreme' were classified as 'with difficulty' and none was classified as 'without difficulty'. This categorisation was selected to determine those who experience any difficulty with toileting rather than the degree of difficulty. 'Without difficulty' was assigned ' 0 ', whereas 'with difficulty' was assigned ' 1 ' for multivariate logistic regression.

\section{Independent variables}

Independent variables were selected to match concepts in the WHO-ICF, which may relate to toileting difficulty (see Figure 1).

\section{Personal factors (PF)}

$\mathrm{PF}$ are contextual factors that are intrinsic to the individual and may relate to an individual's functioning (WHO, 2001). Examples of the PF measured by SAGE Wave 1 include age, education level, gender, marital status and location of residence. Marital status was initially measured using a six-response category (never married, married, co-habiting, separated, divorced, widowed). For the analysis, these responses were measured with a four-response category: 'never married', 'married/co-habiting', 'separated/divorced' and 'widowed'. 


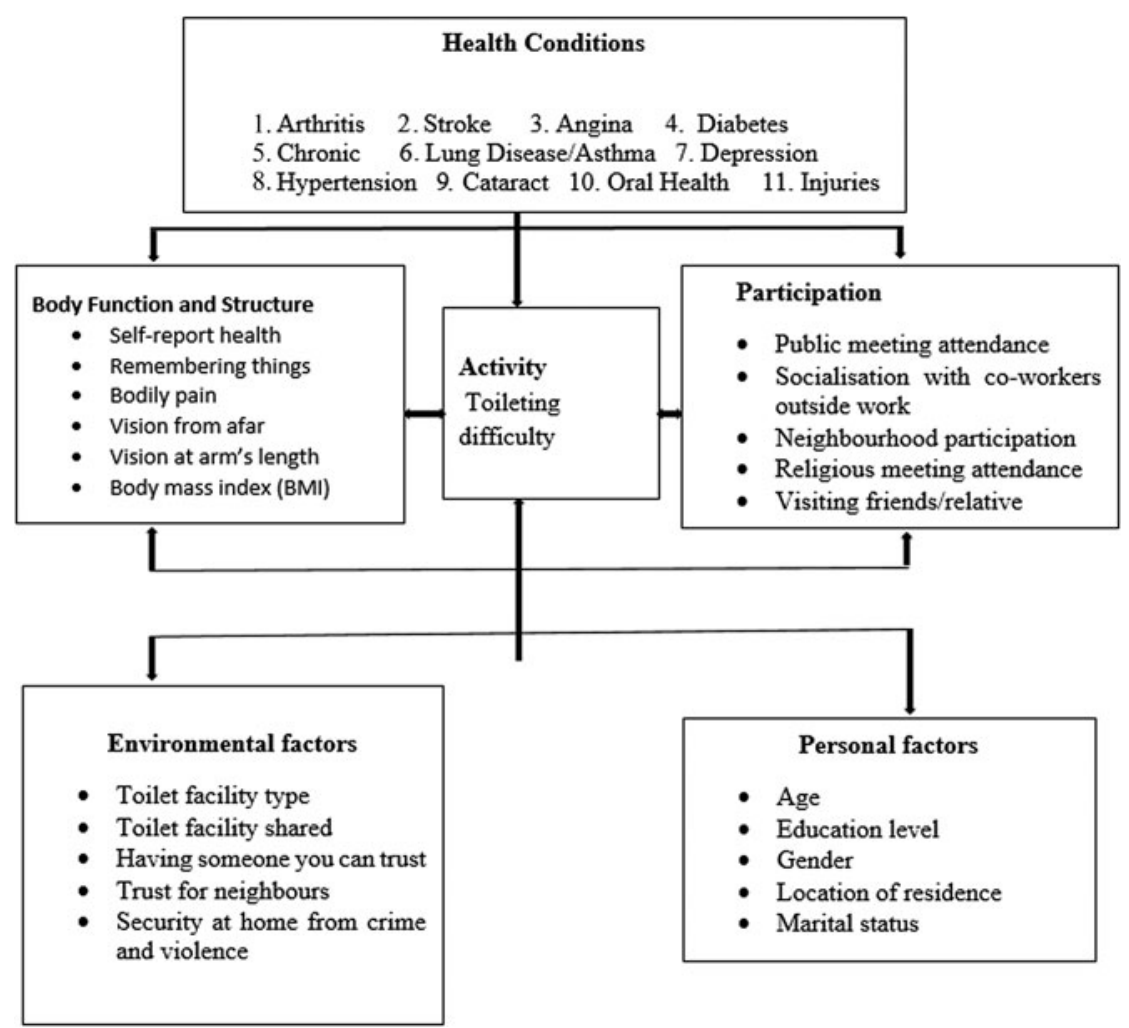

Figure 1. Variables used to study difficulty with toileting among older adults in Ghana in relation to WHO-ICF framework.

\section{Body function and structures (BFS)}

BFS refers to function-level body physiology that affects an individual's quality of life (WHO, 2002). Participants were asked to rate their subjective health status, assessed level of bodily pain, cognition and vision impairments. For each variable, participants were asked to rate how much difficulty they experienced in the previous 30 days using a five-response category (none, mild, moderate, severe, extreme). For each of these variables, the response of 'none' was categorised as 'without difficulty', and 'mild', 'moderate', 'severe' and 'extreme' as 'with difficulty'. Moreover, Body Mass Index (BMI) was also calculated using weight divided by height squared with the response category including underweight $\left(<18.5 \mathrm{~kg} / \mathrm{m}^{2}\right)$, normal weight $\left(18.5-24.9 \mathrm{~kg} / \mathrm{m}^{2}\right)$, overweight $\left(25.0-29.9 \mathrm{~kg} / \mathrm{m}^{2}\right)$ and obese $\left(\geqslant 30.0 \mathrm{~kg} / \mathrm{m}^{2}\right)$.

\section{Health conditions (HC)}

According to the WHO-ICF framework, HC refers to any disease, disorders or injuries that affect the functioning and health of a person (WHO, 2002). Information about the presence of $\mathrm{HC}$ was based on responses to the questions: 'Have you ever been diagnosed with or told you have...?' for arthritis, stroke, 
angina, diabetes, chronic lung disease/asthma, depression, hypertension, cataracts, oral health and/or injuries.

\section{Environmental factors (EF)}

EF refers to the physical, social and attitudinal setting in which older adults in Ghana undertake life activities (WHO, 2002). Physical environmental factors such as toilet facility type were included in this analysis. The question 'What type of toilet facility do members of your household, including you, use?' initially had 12 responses. However, the responses were categorised as 1 = 'toilet facility inside the home' (piped sewer system, septic tank, pit latrine, flush to other location, flush to unknown place), 2 = 'toilet facility outside the home' (ventilated improved pit latrine, pit latrine with slab, pit latrine without a slab, composting toilet, bucket latrine, hanging toilet) and $3=$ 'no facility or bush or field'.

Moreover, participants were asked about their level of trust for others, their neighbourhood, and the level of security from crime and violence at home. With the trust for others, the question was: 'Do you think you have someone you can trust?' This question was asked on a dichotomous response scale, 'yes' or 'no'. Concerning the trust for the neighbourhood, among the questions asked was 'First think about people in your neighbourhood/others, would you say that you can trust them?' These questions were measured with a five-response category (to a great extent, to a very great extent, neither great nor small extent, to a small extent, to a very small extent). These responses were categorised as 'great extent' for 'to a great extent' and 'to a very great extent', whereas 'small extent' was for 'neither great nor small extent', 'to a small extent' and 'to a very small extent'. Concerning the safety of participants at home, they were asked: 'In general, how safe from crime and violence do you feel when you are alone at home?' This question was measured with a five-response category (completely safe, very safe, moderately safe, slightly safe, not safe all). The response was categorised as 'safe' (completely safe, very safe) and 'not safe' (moderately safe, slightly safe, not safe at all).

\section{Participation}

Participation refers to a level of engagement in everyday life (WHO, 2002). SAGE Ghana Wave 1 explored older Ghanaians' involvement in community activities, including working with people in the neighbourhood, socialising with co-workers outside work, religious meeting attendance, attending social meetings or programmes, and visiting friends or relatives. For each of these variables, participants were asked how often in the last 12 months they engaged the activities with a five-response category (never, once or twice per year, once or twice per month, once or twice per week, daily). For each variable, the responses were categorised as 'no' (never) and 'yes' (once or twice per year, once or twice per month, once or twice per week, daily).

\section{Data analysis}

All analysis was facilitated by Stata software (version 15). Descriptive statistics (percentages and frequency) were used to present the prevalence of ADLs and IADLs. 
Chi-square tests (categorical) and $t$-tests (continuous) were used to determine the significant differences between those with and without toileting difficulty on each of the independent variables. Bivariate and multivariable logistic regression was performed to estimate the crude and adjusted odds ratios (AOR) and 95 per cent confidence intervals for the associations between each WHO-ICF component (independent variables) and toileting difficulty (dependent variable). All variables that were at $p<0.05$ on the bivariate analyses were included in the multivariable logistics regression model. Models were built using a backwards stepwise approach for each WHO-ICF domain. The significant variables for each area were then included in nested multivariate models (Models 1-5) with Model 5 including all significant variables from Models 1, 2, 3 and 4. Post-hoc analysis to test for an interaction between gender, marital status and toileting difficulty was also conducted.

\section{Ethical consideration}

Ethical approval for this analysis was obtained from the WHO Ethical Research Committee and University of Newcastle, New South Wales, Australia in keeping with the Declaration of Helsinki.

\section{Results}

\section{Demographic characteristics of participants}

Table 1 presents the demographic characteristics of the participants. Most participants were men $(53.5 \%)$ and the mean age was 60 years. Most participants had no formal education (48.3\%), were living in rural areas (59.0\%) and were married or co-habiting (59.9\%).

\section{Prevalence of 'difficulty' in ADL and IADL items}

The most common functional difficulties involved IADLs, including climbing stairs, standing for long periods, carrying things and walking a long distance. For each functional activity, difficulties were higher among women than men with the exception of eating, where men experienced more difficulty than women. The prevalence of ADL difficulties in terms of rank was (1) transferring (standing up from sitting down, and getting up from lying down); (2) toileting, (3) bathing or washing, (4) dressing and (5) eating. Toileting difficulty was ranked 16 out of the 22 functional items analysed, ahead of moving around inside the home, getting out of the home, extending arms above the shoulder, bathing or washing whole body, getting dressed and eating. Toileting difficulty was ranked second in terms of reported difficulty among five ADL items. Prevalence of difficulty in functional items is presented in Table 2.

\section{Bivariate analysis of toileting difficulty across WHO-ICF components}

Results of the univariate analysis in terms of toileting difficulty and variables according to each of the WHO-ICF components are presented in the tables in the online supplementary material. 
Table 1. Demographic characteristics of participants

\begin{tabular}{lc}
\hline Characteristics & N (\%) \\
\hline Sex: & $2,727(53.5)$ \\
\hline Male & $2,369(46.5)$ \\
\hline Female & \\
\hline Education: & $2,461(48.3)$ \\
\hline No education & $1,214(24.0)$ \\
\hline At most primary completed & $1,214(24.0)$ \\
\hline Senior high completed & $178(3.51)$ \\
\hline University degree and above & \\
\hline Location of residence: & $2,087(41.0)$ \\
\hline Urban & $3,009(59.0)$ \\
\hline Rural & \\
\hline Marital status: & $142(2.82)$ \\
\hline Never married & $3,018(59.9)$ \\
\hline Married/co-habiting & $664(13.2)$ \\
\hline Separated/divorced & $1,219(24.2)$ \\
\hline Widowed & $60.1(14.1)$ \\
\hline Mean age (standard deviation) & \\
\hline
\end{tabular}

\section{Modelling toileting difficulty according to the WHO-ICF framework}

Multivariable regression results for PF are shown in Table 3 (Model 1). After adjusting for other significant PF, the odds of toileting difficulty in females was $1.20(p<0.01)$ times the odds of difficulty in males. Besides, for every one-year increase in age, the odds of toileting difficulty increased by 4 per cent $(p<0.01)$. In terms of education, the odds of toileting difficulty in those who had completed at most primary education was $0.24(p<0.01)$, those who had completed senior high was $0.27(p<0.01)$ and those who had completed atleast a university education was $0.49(\mathrm{p}<0.01)$ less the odds of difficulty in those who had not had any formal education. Although the location of residence was significant in the bivariate analyses, this factor became statistically not significant after adjusting for all other PF. For marital status, the odds of toileting difficulty in the never married was 2.56 $(p<0.001)$, the separated or divorced was $1.18(p>0.05)$, and the widowed was $1.30(p<0.01)$ times the odds of toileting difficulty in the married and co-habiting.

In Model 2, all PF that remained significant in Model 1 were included with all significant BFS items to determine their effect on toileting difficulty among older adults. After adjusting for PF and BFS items, gender was not statistically significantly associated with toileting difficulty.

All other PF remained significant. The odds of toileting difficulty in older adults who reported bad health was $1.70(p<0.001)$ times the odds of difficulty in those 
Table 2. Prevalence of functional difficulties

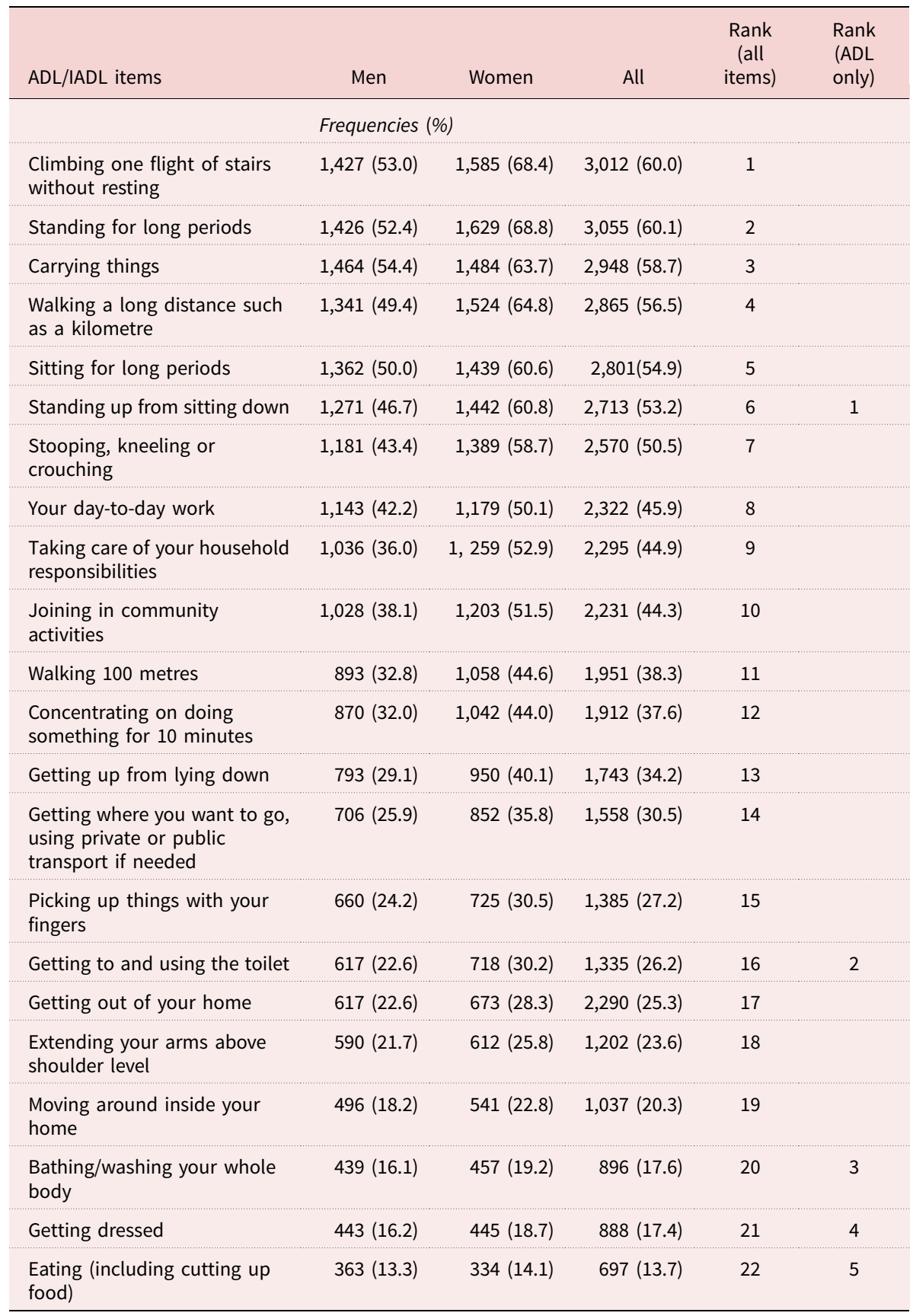

Notes: ADL: activity of daily living. IADL: instrumental activity of daily living. 
Table 3. Modelling toileting difficulty according to the World Health Organization International Classification of Functioning, Disability and Health (WHO-ICF) framework

\begin{tabular}{|c|c|c|c|c|c|c|}
\hline Variables based on ICF component & $\begin{array}{l}\text { Crude odds ratio } \\
\qquad(95 \% \mathrm{Cl})\end{array}$ & Model 1: PF & Model 2: PF + BFS & $\begin{array}{c}\text { Model 3: PF + BFS } \\
+\mathrm{HC}\end{array}$ & $\begin{array}{c}\text { Model 4: } P F+B F S \\
+H C+E F\end{array}$ & $\begin{array}{l}\text { Model 5: PF + BFS } \\
\quad+H C+E F+P\end{array}$ \\
\hline & & \multicolumn{5}{|c|}{ Adjusted odds ratios (95\% Cl) } \\
\hline \multicolumn{7}{|l|}{ Personal factors (PF): } \\
\hline Female (versus male) & $1.47(1.29,1.66)^{\star \star \star}$ & $1.20(1.01,1.42)^{\star \star}$ & $0.92(0.77,1.11)$ & & & \\
\hline Age & $1.05(1.04,1.06)^{\star \star \star}$ & $1.04(1.04,1.05)^{\star \star}$ & $1.02(1.01,1.03)^{\star \star \star}$ & $1.02(1.01,1.02)^{\star \star \star}$ & $1.02(1.02,1.03)^{\star \star \star}$ & $1.02(1.01,1.03)^{\star \star \star}$ \\
\hline \multicolumn{7}{|l|}{ Education: } \\
\hline No education & 1 & 1 & 1 & 1 & 1 & 1 \\
\hline At most primary completed & $0.51(0.43,0.60)^{\star \star \star}$ & $0.76(0.63,0.91)^{\star \star}$ & $0.75(0.62,0.91)^{\star \star}$ & $0.74(0.61,0.90)^{\star \star}$ & $0.77(0.62,0.95)^{\star}$ & $0.78(0.63,0.96)^{\star}$ \\
\hline Senior high completed & $0.44(0.37,0.52)^{\star \star \star}$ & $0.73(0.600 .89)^{\star \star}$ & $0.90(0.73,1.11)$ & $0.90(0.73,1.12)$ & $1.01(0.80,1.26)$ & $1.02(0.81,1.28)$ \\
\hline University degree and above & $0.32(0.21,0.50)^{\star \star \star}$ & $0.51(0.33,0.81)^{\star \star}$ & $0.56(0.35,0.92)^{\star}$ & $0.55(0.33,0.91)^{\star}$ & $0.69(0.41,1.15)$ & $0.77(0.46,1.30)$ \\
\hline $\begin{array}{l}\text { Location of residence: rural } \\
\text { (versus urban) }\end{array}$ & $1.14(1.01,1.30)^{\star}$ & $1.08(0.93,1.24)$ & & & & \\
\hline \multicolumn{7}{|l|}{ Marital status: } \\
\hline Never married & $1.31(0.89,1.94)$ & $2.56(1.67,4.01)^{\star \star \star}$ & $2.76(1.69,4.51)^{\star \star \star}$ & $2.64(1.60,4.33)^{\star \star \star}$ & $2.54(1.52,4.27)^{\star \star \star}$ & $2.42(1.43,4.07)^{\star \star}$ \\
\hline Married/co-habiting & 1 & 1 & 1 & 1 & 1 & 1 \\
\hline Separated/divorced & $1.46(1.20,1.77)^{\star \star \star}$ & $1.18(0.95,1.46)$ & $1.23(0.97,1.55)$ & $1.14(0.91,1.42)$ & $1.12(0.89,1.40)$ & $1.09(0.86,1.38)$ \\
\hline Widowed & $2.41(2.08,2.79)^{\star \star \star}$ & $1.30(1.07,1.57)^{\star \star}$ & $1.28(1.04,1.57)^{\star}$ & $1.22(1.02,1.45)^{\star}$ & $1.16(0.96,1.39)$ & $1.09(0.90,1.31)$ \\
\hline \multicolumn{7}{|l|}{ Body function and structure (BFS): } \\
\hline Bad health (versus good) & $4.03(3.49,4.65)^{\star \star \star}$ & & $1.69(1.43,2.00)^{\star \star \star}$ & $1.67(1.41,1.97)^{\star \star \star}$ & $1.54(1.29,1.83)^{\star \star \star}$ & $1.46(1.23,1.75)^{\star \star *}$ \\
\hline $\begin{array}{l}\text { Difficulty remembering things } \\
\text { (versus no difficulty) }\end{array}$ & $6.71(5.67,7.94)^{\star \star \star}$ & & $3.13(2.58,3.80)^{\star \star \star}$ & $3.13(2.57,3.80)^{\star \star \star}$ & $2.85(2.33,3.49)^{\star \star \star}$ & $2.70(2.20,3.31)^{\star \star \star}$ \\
\hline
\end{tabular}


Table 3. (Continued.)

\begin{tabular}{|c|c|c|c|c|c|c|}
\hline Variables based on ICF component & $\begin{array}{l}\text { Crude odds ratio } \\
\qquad(95 \% \mathrm{Cl})\end{array}$ & Model 1: PF & Model 2: PF + BFS & $\begin{array}{c}\text { Model 3: PF + BFS } \\
+\mathrm{HC}\end{array}$ & $\begin{array}{c}\text { Model 4: PF + BFS } \\
+\mathrm{HC}+\mathrm{EF}\end{array}$ & $\begin{array}{l}\text { Model 5: PF + BFS } \\
\quad+H C+E F+P\end{array}$ \\
\hline Bodily pain (versus no pain) & $14.1(10.4,19.1)^{\star \star \star}$ & & $4.67(3.32,6.53)^{\star \star \star}$ & $4.78(3.39,6.74)^{\star \star \star}$ & $5.20(3.64,7.43)^{\star \star \star}$ & $5.51(3.83,7.92)^{\star \star \star}$ \\
\hline $\begin{array}{l}\text { Difficulty with vision from afar } \\
\text { (versus no difficulty) }\end{array}$ & $4.72(4.02,5.55)^{\star \star \star}$ & & $1.50(1.20,1.87)^{\star \star}$ & $1.45(1.16,1.82)^{\star *}$ & $1.48(1.17,1.86)^{\star \star}$ & $1.52(1.20,1.92)^{\star \star \star}$ \\
\hline $\begin{array}{l}\text { Vision at arm's length (versus no } \\
\text { difficulty) }\end{array}$ & $4.46(3.82,5.21)^{\star \star \star}$ & & $2.08(1.69,2.56)^{\star \star \star}$ & $2.06(1.67,2.54)^{\star \star \star}$ & $2.14(1.72,2.65)^{\star \star \star}$ & $2.15(1.73,2.67)^{\star \star \star}$ \\
\hline \multicolumn{7}{|l|}{ Body Mass Index $\left(\mathrm{kg} / \mathrm{m}^{2}\right)$ : } \\
\hline Underweight & $1.57(1.32,1.88)^{\star \star \star}$ & & $1.19(0.97,1.45)$ & $1.22(0.99,1.49)$ & $1.18(0.96,1.46)$ & $1.14(0.92,1.42)$ \\
\hline Normal weight & 1 & & 1 & 1 & 1 & 1 \\
\hline Overweight & $0.91(0.76,1.08)$ & & $1.14(0.93,1.40)$ & $1.13(0.92,1.39)$ & $1.17(0.94,1.44)$ & $1.19(0.96,1.47)$ \\
\hline Obese & $1.15(0.94,1.40)$ & & $1.38(1.09,1.75)^{\star \star}$ & $1.33(1.04,1.70)^{\star}$ & $1.36(1.06,1.76)^{\star}$ & $1.33(1.03,1.73)^{\star}$ \\
\hline \multicolumn{7}{|l|}{ Health conditions $(\mathrm{HC})$ : } \\
\hline Arthritis & $1.86(1.55,2.23)^{\star \star *}$ & & & $1.05(0.85,1.30)$ & & \\
\hline Stroke & $4.42(3.04,6.44)^{\star \star}$ & & & $2.90(1.84,4.56)^{\star \star \star}$ & $2.84(1.79,4.52)^{\star \star \star}$ & $2.63(1.63,4.23)^{\star \star *}$ \\
\hline Angina & $1.16(0.81,1.67)$ & & & & & \\
\hline Diabetes & $1.50(1.09,2.06)^{*}$ & & & $0.96(0.65,1.41)$ & & \\
\hline Chronic lung disease/asthma & $3.83(1.81,8.12)^{\star \star \star}$ & & & $2.67(1.06,6.71)^{\star}$ & $3.48(1.37,8.84)^{\star \star}$ & $3.29(1.29,8.40)^{\star}$ \\
\hline Depression & $2.09(1.29,3.38)^{\star \star}$ & & & $1.20(0.69,2.09)$ & & \\
\hline Hypertension & $1.39(1.16,1.67)^{\star \star \star}$ & & & $0.89(0.71,1.11)$ & & \\
\hline Cataract & $2.28(1.74,2.97)^{\star \star \star}$ & & & $1.26(0.93,1.72)$ & & \\
\hline Oral health & $1.81(1.25,2.60)^{\star \star}$ & & & $0.96(0.62,1.46)$ & & \\
\hline Injuries & $1.54(0.99,2.39)$ & & & & & \\
\hline
\end{tabular}




\begin{tabular}{|c|c|c|c|}
\hline $\begin{array}{l}\text { Someone you can trust or } \\
\text { confide: no (versus yes) }\end{array}$ & $1.99(1.72,2.29)^{\star \star \star}$ & $1.92(1.59,2.32)^{\star \star \star}$ & $1.87(1.54,2.27)^{\star \star \star}$ \\
\hline $\begin{array}{l}\text { Neighbourhood trust level: small } \\
\text { extent (versus great extent) }\end{array}$ & $1.81(1.59,2.05)^{\star \star \star}$ & $1.60(1.35,1.88)^{\star \star \star}$ & $1.56(1.32,1.84)^{\star \star \star}$ \\
\hline $\begin{array}{l}\text { Security at home from crime and } \\
\text { violence: not safe (versus safe) }\end{array}$ & $1.05(0.66,1.67)$ & & \\
\hline \multicolumn{4}{|l|}{ Toilet facility type: } \\
\hline Toilet facility inside home & $0.71(0.57,0.87)^{\star \star}$ & $0.66(0.51,0.86)^{\star \star}$ & $0.68(0.52,0.88)^{\star \star}$ \\
\hline Toilet facility outside home & 1 & 1 & 1 \\
\hline No facilities (bush, field) & $1.30(1.12,1.52)^{\star \star}$ & $1.55(1.28,1.88)^{\star \star \star}$ & $1.53(0.52,0.87)^{\star \star \star}$ \\
\hline Toilet facility shared: no (versus yes) & $0.89(0.74,1.07)$ & & \\
\hline \multicolumn{4}{|l|}{ Participation $(\mathrm{P})$ : } \\
\hline $\begin{array}{l}\text { Public meeting attendance: no } \\
\text { (versus yes) }\end{array}$ & $2.44(2.15,2.78)^{\star \star \star}$ & & $1.25(1.04,1.51)^{\star}$ \\
\hline $\begin{array}{l}\text { Socialised with co-workers } \\
\text { outside work: no (versus yes) }\end{array}$ & $1.84(1.62,2.08)^{\star \star \star}$ & & $1.24(1.03,1.48)^{\star}$ \\
\hline $\begin{array}{l}\text { Neighbourhood participation } \\
\text { level: no (versus yes) }\end{array}$ & $2.11(1.86,2.40)^{\star \star \star}$ & & $0.94(0.78,1.15)$ \\
\hline $\begin{array}{l}\text { Religious meeting attendance: } \\
\text { no (versus yes) }\end{array}$ & $1.98(1.67,2.35)^{\star \star \star}$ & & $1.30(1.01,1.67)^{\star}$ \\
\hline $\begin{array}{l}\text { Visiting friends/relative: } \\
\text { no (versus yes) }\end{array}$ & $2.02(1.70,2.39)^{\star \star \star}$ & & $0.99(0.77,1.27)$ \\
\hline
\end{tabular}

Note: $\mathrm{Cl}$ : confidence interval.

Significance levels: ${ }^{\star} p<0.05,{ }^{\star *} p<0.01,{ }^{\star \star *} p<0.001$. 
who reported their health as good, after adjusting for PF and other BFS factors. The odds of toileting difficulty in older adults who have difficulty remembering things was $3.09(p<0.01)$ times the odds of difficulty in older adults who do not have difficulty with memory function. The odds of difficulty in older adults having bodily pain was $4.68(p<0.001)$ times the odds of difficulty in those who do not have bodily pain. In terms of distant vision, the odds of toileting difficulty in older adults having difficulty seeing from afar is $1.49(p<0.01)$ times the odds of toileting difficulty in older adults who have no difficulty seeing from afar. After adjusting for PF and other BFS, the toileting difficulty in older adults having difficulty with shortdistance vision is $2.07(p<0.001)$ times the odds of difficulty in those who do not have difficulty seeing. Moreover, the obese older adults were more likely to have toileting difficulty compared to those with normal weight ( $\mathrm{AOR}=1.38, p<0.01$ ).

In Model 3, all items that remained significant in Model 2 were added to HC variables that were significant during the bivariate analysis. After adjusting for other PF, BFS and HC, there was minimal change in estimates for PF or factors reflecting BFS.

Concerning the HC, older adults reporting having a stroke and chronic lung disease were significantly more likely to report toileting difficulty after adjusting for PF, BFS, and other HC. The odds of toileting difficulty in older adults having a stroke was $2.92(p<0.001)$ times those not having a stroke. Additionally, the odds of toileting difficulty in those having chronic lung disease such as cancer was $2.61(p<0.05)$ times those not having it. All other HC (arthritis, angina, diabetes, depression, hypertension, cataract and oral health problems) were no longer significant at 0.05 after adjustment for PF, BFS and other HCs.

Model 4 included all significant variables under PF, BFS, HC, together with EFs that were significant during the bivariate analysis. Concerning the EF, the odds of toileting difficulty in those who do not have someone to confide in was 1.91 $(p<0.001)$ times the odds of toileting difficulty in those who have someone to trust in. The odds of toileting difficulty in those who have limited neighbourhood trust is $1.61(p<0.001)$ times the odds of toileting difficulty in those who have full neighbourhood trust. The odds of toileting difficulty in those who have a toileting facility inside the home was 0.31 less than, and the odds of toileting difficulty in those who have no toilet facilities (bush and fields) was $1.54(p<0.001)$ times more than those with toileting facilities outside the home. The final model, Model 5, included all PF, BFS, HC and EF variables that became significant in Model 4 together with all participation variables that were significant during the bivariate analysis to understand how all the various components of the WHO-ICF influence toileting difficulty in older adults, including their participation in social and community activities.

Regarding the participation variables, the odds of toileting difficulty among older adults who did not participate in public meetings was 1.26 (dependently significant at $p<0.05$ ) times the odds of toileting difficulty in those who did participate. The odds of toileting difficulty in those who did not socialise with co-workers outside work was 1.24 (dependently significant at $p<0.05$ ) times the odds of toileting difficulty in those who socialised with co-workers outside work. The odds of toileting difficulty in those who did not attend religious meetings was 1.30 (dependently significant at $p<0.05$ ) times the odds of difficulty in those who attended. The 
neighbourhood participation level and visiting friends or relatives were not statistically significantly related to toileting difficulty.

Post-hoc analysis to test interactions between gender, marital status and toileting difficulty revealed that interaction existed between female and never married ( $p=$ 0.04), implying that the relationship between female and never married appears to be different from the relationship between males and never married. There was no interaction between female and divorced/separated $(p=0.17)$, and female and widowed $(p=0.31)$. Moreover, interaction existed between obese BMI and the widowed marital status $(p=0.01)$.

\section{Discussion}

Older adults included in this current study had a range of ADL and IADL difficulties. In particular, toileting difficulty was identified to be multifactorial with personal, health, societal and environmental influences. To our knowledge, this is the first study that has examined the prevalence of specific functional difficulties and provides valuable information for health professionals and policy makers in meeting the care needs of older adults. The discussion is structured under three broad themes, including the prevalence of functional difficulties, factors relating to toileting difficulty and the lessons learnt from the application of the WHO-ICF framework.

\section{Prevalence of functional difficulties}

Overall, the majority of participants experienced difficulty in IADLs rather than in ADLs, including climbing stairs, carrying things, walking a long distance and taking care of household responsibilities. These findings enhance our understanding of the disability Biritwum et al. (2016) reported that older adults in Ghana experience by drawing attention to the nature of specific functional difficulty as experienced by older adults. Findings from previous studies corroborate the finding that older adults experience difficulties in IADLs compared to ADLs (Bowling et al., 2012; Gontijo et al., 2016; Vaughan et al., 2016; Carmona-Torres et al., 2019). Moreover, in this current study, the IADL climbing one flight of stairs without resting was the most prevalent functional difficulty $(60.0 \%)$ contrary to difficulty in performing severe household work (34\%) found in a study conducted in by Spain Carmona-Torres et al. (2019). The difference could be because of the economic wealth existing between Ghana and Spain. Generally, IADLs are often more complex in terms of cognitive and physical demands and are often where older adults first start experiencing functional difficulties. The difficulties older adults experience with IADLs may imply that physical environmental factors in Ghana may not be supportive for older people to manage their functional difficulties as highlighted by the WHO (2014). In the western world, due to the availability of functional aids, these IADLs may be lost in the later periods of their life, or may not be lost at all. Often, in westernised countries modern technologies such as lifts, mobility aids and the use of forklifts are more accessible to older adults instead of using their strength, and so difficulties in these functional activities are not as prevalent as in developing country like Ghana. It is noted that in each of the 
IADLs, the prevalence of difficulty was higher in women compared to men. These difficulties may result in reduced quality of life, enhance health-care expenditure, elder abuse and eventually lead to a premature death (Chen and Sloan, 2015; Wu et al., 2016; Kuo et al., 2017; Tareque et al., 2017; Carmona-Torres et al., 2020), necessitating the need for a holistic intervention.

The prevalence of ADL difficulties in order of occurrence (transfers, toileting, bathing, dressing and eating) identified in this current study are similar to the previous findings of a study of Chinese older adults (Fong and Feng, 2018), confirming that difficulties experienced in ADLs may be contextual. The finding that prevalence of difficulty was higher in women compared to men except for eating indicates the need for health and social interventions to help minimise or manage the impact of these difficulties on functional abilities. The differential experience of difficulty in ADLs among men and women found in this study corroborates mainstream research findings that women generally report poor health and experience high functional disability compared to men (Fried et al., 2004; Saito et al., 2014; Stewart Williams et al., 2015; Biritwum et al., 2016). Looking at the order of the ADL difficulties found in this study indicates that in the Ghanaian context, activities that require upper-extremity strength such as toileting occurs at the early stages of older adults' lives. This finding is contrary to the hierarchical loss of ADLs in westernised regions where they are lost at the later stages of older adults' lives (Dunlop et al., 1997; Fong and Feng, 2018), which could be explained by the variation in levels of development determining the availability of functional aids. Although toileting difficulty did not emerge as the highest prevalence functional difficulty, it was important for further consideration because of its association with loss of independence among older adults. Since the mainstream research shows that older adults, including those in Ghana, can improve their ADL and IADL functioning (Iwaya et al., 2017), interventions such as physical exercise, use of aids or devices, and personal care should be available to them to help older adults relearn the lost abilities.

More health professionals such as geriatricians and psychotherapists should be trained about the needs of older adults to ensure early detection of any difficulties with ADLs or IADLs to reduce the possibility of impairment. In Ghana, health professionals specialising in the health and functional abilities of older adults are few (WHO, 2014), drawing attention to the need for more trained health and social professionals to support older adults at the onset of any disability.

\section{Factors associated with toileting difficulty}

Toileting difficulty was identified to be multifaceted, meaning that a holistic assessment of toileting that incorporates societal and environmental influences is needed to ensure an accurate reflection of older adult care needs. Research related to participation restrictions also acknowledged the interrelatedness of functional difficulties, again supporting the need for holistic assessment (Fairhall et al., 2011; Liu, 2017).

The finding that older adults who reported perceived bad health (a BFS factor) are more likely to have toileting difficulty is consistent with the existing evidence that self-reported health was significantly associated with functional difficulties (Mun-San Kwan et al., 2011; Burke et al., 2012). Older adults who had bodily 
pain were more likely to have toileting difficulty. This adds to the finding that bodily pain is significantly related to IADLs (Mun-San Kwan et al., 2011). Having bodily pain may mean even having trouble standing, walking and sitting on the toilet to free one's bowel. Most toilet facilities in Ghana are of a squat and sit nature (Osumanu and Kosoe, 2013), so older adults having bodily pain may have difficulty freeing their bowels. Older adults having difficulty with memory were also more likely to have toileting difficulty, supporting the finding that a significant association exists between cognitive impairment and people with ADL difficulties (Paúl et al., 2010). In this study, older adults with poor vision (both short and distant) were more likely to have difficulty with toileting, supporting previous evidence that a significant relationship exists between an older adult with visual impairment and their ability to carry out ADLs (Gray et al., 2006). Having vision difficulty will mean that older adults may need to be accompanied to the toilet, or it will take a longer time for them to walk to the toilet themselves and even to undress and dress afterwards.

The finding in this current study that environmental factors (both lack of trust for others and neighbours) were strongly significantly associated with toileting difficulty support the existing evidence that older women with a higher level of mistrust for others had a higher onset of disability (Aida et al., 2013). In Ghana, where most of the toilet facilities are situated outside the home (Peprah et al., 2015), trust for individuals and neighbours are necessary for toileting to be completed. In this study, both having a toilet facility inside the home and having no toilet facility were significantly associated with toileting difficulty, indicating that intrinsic factors such as advanced age and extrinsic factors such as a trust for others may together contribute to the significant associations with toileting. Out of the nine health conditions, stroke and chronic lung disease became significantly associated with toileting difficulty, with stroke having stronger evidence of a relationship with toileting difficulty. The results support previous findings that stroke is associated with functional difficulties among older adults (Siviero et al., 2016). This finding suggests that health professionals should investigate potential difficulties with post-stroke older people as they are likely to have difficulties with toileting and require intervention. Older adults with chronic lung disease like asthma were more likely to have toileting difficulty. Arthritis, angina, diabetes, depression, hypertension, cataract and oral health were not significantly associated with toileting difficulty. Although these chronic conditions were significant on the bivariate analysis, their lack of significance may be due to their interaction with other factors like body function and impairment.

The finding that older adults with advanced age were more likely to have toileting difficulty is similar to findings that age was significantly associated with loss of ADL ability (Covinsky et al., 2003; Abellán et al., 2015). While SAGE Wave 1 data sampled older adults from the community, Convinsky et al. (2003) sampled participants from the hospital. Yet, a similar result implies that the influence of advanced age on toileting difficulty is not restricted to the home setting. Older adults who had only completed primary school being more likely to have toileting difficulty is consistent with previous studies (Abellán et al., 2015; Biritwum et al., 2016).

Moreover, never-married older Ghanaians were more likely to have toileting difficulty, supporting available evidence that a significant relationship exists between 
marital status and stability in mobility (Femia et al., 1997). The never-married older adults may have limited social support; therefore, social welfare interventions should favour the never-married older adults in Ghana because they are likely to have toileting difficulty. Gender was not associated with toileting difficulty, contradicting previous evidence that older adults with ADL difficulties are mostly women (Abellán et al., 2015; Biritwum et al., 2016). The variation in the findings may not be due to a cultural difference, but rather due to an interaction that gender had with marital status in relation to toileting difficulty. In this regard, never married interacted with being female, making the relationship between toileting difficulty and sex insignificant in the current study.

As found in this study, older adults who do not attend public meetings, associate with co-workers and attend religious meetings were more likely to have toileting difficulty, supporting the available evidence that a significant relationship exists between social participation and functional disability (Aida et al., 2013). The social participations factors make sense in the Ghanaian context because older adults cherish participation, including church gatherings and wedding ceremonies (Awuviry-Newton et al., 2020b), and so when older adults do not satisfy their cherished life activities, it may affect their overall health including their toileting difficulty. Given the decline in the traditional extended family system in Ghana (Nukunya, 2003; Ofori-Dua, 2014; Awuviry-Newton et al., 2017), the emotional aspect of social support may be unavailable, so when older adults fail to attend a social gathering, their emotional wellbeing may be impaired, thereby affecting their toileting abilities. This finding shows how participation is essential in determining the health of older adults.

The multifactorial nature of toileting difficulty among older adults requires multi-disciplinary interventions, including health professionals, social workers, researchers, policy makers and all stakeholders. For health professionals who seek to enhance the toileting ability of post-stroke and poor memory patients, this study offers relevant factors to investigate through assessment and intervention. For social welfare professionals such as social workers who seek to improve the social health of older adults, this study offers an insight into crucial variables such as environmental and participation factors worthy of inquiry and intervention. The strength of this study comes from the use of model predictors of toileting difficulty using the WHO-ICF framework, making it pioneering research to employ all its components to study the effect on toileting difficulty. It is noted that when matching the variables selected from the SAGE individual questionnaire and household questionnaire to the WHO-ICF framework, there was a likelihood of misclassification. Moreover, the current study did not include more variables on built environments, which may have a strong association with toileting difficulty.

\section{Applying the WHO-ICF framework in relation to toileting difficulty}

Employing the WHO-ICF in studying factors echoing our understanding of the toileting needs of older adults in Ghana, the study revealed that toileting difficulty among older adults is holistically related. The WHO-ICF posits that the nature of an individual's (a) body function and structure, (b) activity limitation and (c) participation restrictions are understood contextually, that is, from an individual's (d) personal and (e) environmental factors. After the full modelling process, we 
determined that at least two variables from each of the five components of the WHO-ICF are significantly related to toileting difficulty, meaning that the components of the WHO-ICF are interrelated, and together they influence the toileting difficulty among older adults. Similar findings were found in studies that used the WHO-ICF to study participation restrictions among older adults (Fairhall et al., 2011; Liu, 2017).

Among the components of the WHO-ICF, all variables under body function and structure and environmental factors were significantly associated with toileting difficulty. The next strongly associated factors to toileting difficulty are age, primary school completion and never married, all being PF. Older adults with advanced age were more likely to have toileting difficulty. This is similar to findings that age was significantly associated with loss of ADL ability (Covinsky et al., 2003; Abellán et al., 2015; Biritwum et al., 2016). In this study, participation factors were the least associated factors with toileting difficulty, similar to the finding of a previous study (Aida et al., 2013). In a nutshell, the WHO-ICF framework is appropriate to help understand the functional needs of older adults mostly from the health, personal and environmental perspectives.

\section{Conclusion}

A significant level of functional difficulties existed among older adults in Ghana, with a higher prevalence in women compared to men. Specifically, older adults in Ghana experience high difficulty with IADLs compared to ADLs. Toileting difficulty, an activity-restriction variable, is a concern for older adults in Ghana and should be investigated by social and health professionals working with these clients. Since social workers are mandated to ensure the health and social needs of people, including older adults, they can explore their role on helping to maximise functional ability in old age and help disseminate the findings to older adults, their caregivers and families. Evidence in Ghana shows that social workers express interest in devising strategies to support older adults (Awuviry-Newton et al., 2020), it therefore requires the state's support to help social workers achieve their aim. Moreover, public health professionals could work with communities to identify the risk factors that can reduce functional ability among older adults. They can help influencing public health policies to provide for the mobility needs of older adults, which may include visual and walking aids. Given that the difficulties in toileting were identified as multifactorial with the application of the WHO-ICF framework, intervention should be developed to target the modifiable associated factors of toileting difficulty, including attention to the social and built environment. Future research should focus on an in-depth qualitative exploration of the WHO-ICF so that older adults' experiences with toileting are understood, and intervention programmes can be developed. Moreover, research to track the trend of this functional difficulty among older adults will be particularly relevant for researchers, health professionals and policy makers. In Ghana, there are many vulnerable groups whose circumstances might be similar to that of older adults, and so we recommend that future research should employ the same methodology to study vulnerable groups such as those living with a disability regardless, to provide information on how best they can be supported. 
Supplementary material. The supplementary material for this article can be found at https://doi.org/10. 1017/S0144686X21000453

Acknowledgements. We are grateful to the participants of WHO Study on global AGEing and adult health (SAGE) Ghana project (Wave 1) for their time and participation, and acknowledge the expertise and contributions of investigators and survey teams. We are grateful to Professor Mel Gray for her initial contact and the Research Centre for Generational Health and Ageing for making educational resources available for data analysis and write-up. Moreover, we are grateful to Linda Smythe and Natalie Soeters for their assistance with proofreading.

Financial support. This work was supported by the University of Newcastle International Postgraduate Research Scholarship (UNIPRS); the University of Newcastle Research Scholarship Central 50:50 (UNRSC50:50); and the Australian Research Council Centre of Excellence in Population Ageing Research (project number CE170100005).

Conflict of interest. The authors declare no conflicts of interest.

Ethical standards. Ethical approval for this analysis was obtained from the WHO Ethical Research Committee and the University of Newcastle, New South Wales, Australia in keeping with the Declaration of Helsinki. The ethical approval reference number from the University of Newcastle is H-2018-0143.

\section{References}

Abellán A, Rodríguez-Laso Á, Pujol R and Barrios L (2015) A higher level of education amplifies the inverse association between income and disability in the Spanish elderly. Aging Clinical and Experimental Research 27, 903-909.

Aida J, Kondo K, Kawachi I, Subramanian S, Ichida Y, Hirai H, Kondo N, Osaka K, Sheiham A and Tsakos G (2013) Does social capital affect the incidence of functional disability in older Japanese? A prospective population-based cohort study. Journal of Epidemiology \& Community Health 67, 42-47.

Awuviry-Newton K, Byles J and Tavener M (2017) Evolution of familial care and support for older people in Ghana: a literature review. Paper presented at Maintaining a Work-Life Balance as a Researcher, Perth, Western Australia. (6-7 November 2017)

Awuviry-Newton K, Nkansah JO and Ofori-Dua K (2020a) Attributions of elder neglect: a phenomenological study of older people in Ghana. Health \& Social Care in the Community 28, 2172-2178.

Awuviry-Newton K, Tavener M, Wales K and Byles J (2020b) Interpretative phenomenological analysis of the lived experiences of older adults regarding their functional activities in Ghana. Journal of Primary Care \& Community Health 11. Available at https://doi.org/10.1177/2150132720931110.

Awuviry-Newton K, Wales K, Tavener M and Byles J (2020c) Do factors across the World Health Organisation's International Classification of Functioning, Disability and Health framework relate to caregiver availability for community-dwelling older adults in Ghana? PLOS ONE 15, e0233541.

Awuviry-Newton K, Tavener M, Wales K and Byles J (2020) The roles and capacities of social workers in the lives of older adults seeking healthcare and their caregivers in Ghana. Health \& Social Care in the Community 1, 1-11. 10.1111/hsc.13121.

Awuviry-Newton K, Ofori-Dua K and Newton A (in press-a) Understanding transportation difficulty among older adults in Ghana from the perspective of World Health Organisation's Healthy Ageing framework: lessons for improving social work practice with older adults. British Journal of Social Work. Available online doi:10.1093/bjsw/bcaa247.

Biritwum RB, Mensah G, Minicuci N, Yawso AE, Naidoo N, Chatterji S and Kowal P (2013a) Household characteristics for older adults and study background from SAGE Ghana Wave 1. Global Health Action 6, 20096.

Biritwum RB, Mensah G, Yawson AE and Minicuci N (2013b) Study on Global AGEing and Adult Health (SAGE), Wave 1: The Ghana National Report. Geneva: World Health Organization.

Biritwum R, Minicuci N, Yawson A, Theou O, Mensah G, Naidoo N, Wu F, Guo Y, Zheng Y and Jiang Y (2016) Prevalence of and factors associated with frailty and disability in older adults from China, Ghana, India, Mexico, Russia and South Africa. Maturitas 91, 8-18. 
Bloom DE and Luca DL (2016) The global demography of aging: facts, explanations, future. In Woodland $\mathrm{AD}$ and Piggott J (eds). Handbook of the Economics of Population Aging, Vol. 1. Amsterdam: Elsevier, pp. 3-56.

Bowling CB, Fonarow GC, Patel K, Zhang Y, Feller MA, Sui X, Blair S, Alagiakrishnan K, Aban IB and Love TE (2012) Impairment of activities of daily living and incident heart failure in community-dwelling older adults. European Journal of Heart Failure 14, 581-587.

Burke KE, Schnittger R, O'Dea B, Buckley V, Wherton JP and Lawlor BA (2012) Factors associated with perceived health in older adult Irish population. Aging \& Mental Health 16, 288-295.

Butler RN, Miller RA, Perry D, Carnes BA, Williams TF, Cassel C, Brody J, Bernard MA, Partridge L, Kirkwood T and Martin GM (2008) New model of health promotion and disease prevention for the 21st century. BMJ 337, a399.

Carmona-Torres JM, Rodríguez-Borrego MA, Laredo-Aguilera JA, López-Soto PJ, Santacruz-Salas E and Cobo-Cuenca AI (2019) Disability for basic and instrumental activities of daily living in older individuals. PLOS ONE 14, e0220157.

Carmona-Torres JM, Carvalhal R, Gálvez-Rioja RM, Ruiz-Gandara Á, Goergen $T$ and Rodríguez-Borrego MA (2020) Elder abuse in the Iberian Peninsula and Bolivia: a multicountry comparative study. Journal of Interpersonal Violence 35, 4303-4326.

Chen Y and Sloan FA (2015) Explaining disability trends in the US elderly and near-elderly population. Health Services Research 50, 1528-1549.

Covinsky KE, Palmer RM, Fortinsky RH, Counsell SR, Stewart AL, Kresevic D, Burant CJ and Landefeld CS (2003) Loss of independence in activities of daily living in older adults hospitalized with medical illnesses: increased vulnerability with age. Journal of the American Geriatrics Society 51, 451-458.

Darkwa OK (2000) Toward a comprehensive understanding of the needs of elderly Ghanaians. Ageing International 25, 65-79.

Debpuur C, Welaga P, Wak G and Hodgson A (2010) Self-reported health and functional limitations among older people in the Kassena-Nankana District, Ghana. Global Health Action 3, 54-63.

DuBeau CE, Kuchel GA, Johnson II T, Palmer MH and Wagg A (2010) Incontinence in the frail elderly: report from the 4th International Consultation on Incontinence. Neurourology and Urodynamics 29, $165-178$.

Dunlop DD, Hughes SL and Manheim LM (1997) Disability in activities of daily living: patterns of change and a hierarchy of disability. American Journal of Public Health 87, 378-383.

Fairhall N, Sherrington C, Kurrle SE, Lord S and Cameron I (2011) ICF participation restriction is common in frail, community-dwelling older people: an observational cross-sectional study. Physiotherapy 97, 26-32.

Femia EE, Zarit SH and Johansson B (1997) Predicting change in activities of daily living: a longitudinal study of the oldest old in Sweden. Journals of Gerontology: Psychological Sciences and Social Sciences 52B, P294-P302.

Fong JH and Feng J (2018) Comparing the loss of functional independence of older adults in the US and China. Archives of Gerontology and Geriatrics 74, 123-127.

Fried LP, Ferrucci L, Darer J, Williamson JD and Anderson G (2004) Untangling the concepts of disability, frailty, and comorbidity: implications for improved targeting and care. Journals of Gerontology: Biological Sciences and Medical Sciences 59A, M255-M263.

Ghana Statistical Service (2013) Population and Housing Census Report. Accra: Ghana Statistical Service. Available at www.statsghana.gov.gh/docfiles/2010phc/National_Analytical_Report.pdf.

Gontijo CF, Mambrini JVdM, Luz TCB and Loyola Filho AId (2016) Association between disability and social capital among community-dwelling elderly. Revista Brasileira de Epidemiologia 19, 471-483.

Gray CS, Karimova G, Hildreth AJ, Crabtree L, Allen D and O'Connell JE (2006) Recovery of visual and functional disability following cataract surgery in older people: Sunderland Cataract Study. Journal of Cataract \& Refractive Surgery 32, 60-66.

Grimsland F, Seim A, Borza T and Helvik AS (2019) Toileting difficulties in older people with and without dementia receiving formal in-home care - a longitudinal study. Nursing Open 6, 1055-1066.

Hunskaar S, Arnold E, Burgio K, Diokno A, Herzog A and Mallett V (2000) Epidemiology and natural history of urinary incontinence. International Urogynecology Journal 11, 301-319.

Iwaya T, Doi T, Seichi A, Hoshino Y, Ogata T and Akai M (2017) Characteristics of disability in activity of daily living in elderly people associated with locomotive disorders. BMC Geriatrics 17, 165. 
Jones A (2009) Racial Differences in Functioning Among Elderly Nursing Home Residents, 2004. Washington: US Department of Health and Human Services, Centers for Disease Control and Prevention.

Katz S, Downs TD, Cash HR and Grotz RC (1970) Progress in development of the index of ADL. The Gerontologist 10, 20-30.

Kowal P, Chatterji S, Naidoo N, Biritwum R, Fan W, Lopez Ridaura R, Maximova T, Arokiasamy P, Phaswana-Mafuya N and Williams S (2012) Data resource profile: the World Health Organization Study on global AGEing and adult health (SAGE). International Journal of Epidemiology 41, 1639-1649.

Kuo HT, Lin KC, Lan CF and Li IC (2017) Activities of daily living trajectories among institutionalised older adults: a prospective study. Journal of Clinical Nursing 26, 4756-4767.

Liu JYW (2017) The severity and associated factors of participation restriction among community-dwelling frail older people: an application of the International Classification of Functioning, Disability and Health (WHO-ICF). BMC Geriatrics 17, 43.

McGrath J, Saha S, Al-Hamzawi A, Alonso J, Bromet EJ, Bruffaerts R, Caldas-de-Almeida JM, Chiu WT, De Jonge P and Fayyad J (2015) Psychotic experiences in the general population: a cross-national analysis based on 31261 respondents from 18 countries. JAMA Psychiatry 72, 697-705.

Morris JN, Fries BE and Morris SA (1999) Scaling ADLs within the MDS. Journals of Gerontology: Biological Sciences and Medical Sciences 54A, M546-M553.

Mun-San Kwan M, Lin Shen, CH, Close JC and Lord SR (2011) Sensorimotor function, balance abilities and pain influence Timed Up and Go performance in older community-living people. Aging Clinical and Experimental Research 23, 196-201.

Nkansah OJ, Awuviry-Newton K, Gyasi M, Newton A and Boateng ASA (2021) 'Who doesn't have challenges? I have a lot of challenges': exploring the challenges and coping strategies of neglected older adults in Ghana. Journal of Cross-cultural Gerontology 36, 91-104.

Nukunya GK (2003) Tradition and Change in Ghana: An Introduction to Sociology. Accra: University Press.

Ocansey S, Awusabo-Asare K, Kumi-Kyereme A and Boadi-Kusi SB (2013) Ocular health of the emerging elderly population in Ghana: evidence from a peri-urban community. Healthy Aging \& Clinical Care in the Elderly 5, 21-31.

Ofori-Dua K (2014) Extended Family Support and Elderly Care in Bamang, Ashanti Region of Ghana (PhD thesis). University of Ghana, Accra.

Orji BC, Rao N, Thompson E and Brieger WR (2017) Community health workers provide integrated community case management using malaria rapid diagnostic test kits. Research in Social and Administrative Pharmacy 13, 875-879.

Osumanu IK (2007) Environmental concerns of poor households in low-income cities: the case of the Tamale Metropolis, Ghana. GeoJournal 68, 343-355.

Osumanu IK and Kosoe EA (2013) Where do I answer nature's call? An assessment of accessibility and utilisation of toilet facilities in Wa, Ghana. Ghana Journal of Geography 5, 17-31.

Paúl C, Ribeiro O and Santos P (2010) Cognitive impairment in old people living in the community. Archives of Gerontology and Geriatrics 51, 121-124.

Peprah D, Baker KK, Moe C, Robb K, Wellington N, Yakubu H and Null C (2015) Public toilets and their customers in low-income Accra, Ghana. Environment and Urbanization 27, 589-604.

Quansah K (2010) World Toilet Day and the challenges of access to toilets in Ghana schools. Ghana Business News. (20 November 2019)

Saito E, Ueki S, Yasuda N, Yamazaki S and Yasumura S (2014) Risk factors of functional disability among community-dwelling elderly people by household in Japan: a prospective cohort study. $B M C$ Geriatrics 14, 93 .

Schulz R, Tompkins CA, Wood D and Decker S (1987) The social psychology of caregiving: physical and psychological costs of providing support to the disabled. Journal of Applied Social Psychology 17, 401-428.

Silva JPd, Jesus-Moraleida Fd, Felicio DC, Queiroz BZd, Ferreira ML and Pereira LSM (2019) Biopsychosocial factors associated with disability in older adults with acute low back pain: BACE-Brasil study. Ciência \& Saúde Coletiva 24, 2679-2690.

Siviero P, Zambon S, Limongi F, Castell MV, Cooper C, Deeg DJ, Denkinger, MD, Dennison, EM, Dennison, Edwards, MK and Gesmundon, Atonnellaet al. (2016) How hand osteoarthritis, comorbidity, and pain interact to determine functional limitation in older people: observations from the European Project on OSteoArthritis Study. Arthritis \& Rheumatology 68, 2662-2670. 
Songsore J and McGranahan G (1993) Environment, wealth and health: towards an analysis of intra-urban differentials within the Greater Accra Metropolitan Area, Ghana. Environment and Urbanization 5, 10-34.

Stewart Williams J, Kowal P, Hestekin H, O’Driscoll T, Peltzer K, Yawson A et al.,Biritwum, R. Maximova, T. Salinas Rodriguez, A. Manrique Espinoza, B. Wu, F. Arokiasamy, P. Chatterji and SAGE collaborators (2015) Prevalence, risk factors and disability associated with fall-related injury in older adults in lowand middle-income countries: results from the WHO Study on global AGEing and adult health (SAGE). BMC Medicine 13, 147.

Talley KM, Wyman JF, Bronas UG, Olson-Kellogg BJ, McCarthy TC and Zhao H (2014) Factors associated with toileting disability in older adults without dementia living in residential care facilities. Nursing Research 63, 94-104.

Tareque MI, Tiedt AD, Islam TM, Begum S and Saito Y (2017) Gender differences in functional disability and self-care among seniors in Bangladesh. BMC Geriatrics 17, 177.

United Nations (2017) World Population Prospects: The 2017 Revision, Vol. 1, Comprehensive Tables. New York, NY: United Nations.

United Nations Department of Economic and Social Affairs, Population Division (2015) Directory of Research on Ageing in Africa: 2004-2015 (ST/ESA/SER.A/391). New York, NY: United Nations.

United Nations Department of Economic and Social Affairs, Population Division (2019) World Population Prospects 2019. New York, NY: United Nations.

Van der Geest S (1998) Yebisa Wo Fie: growing old and building a house in the Akan. Journal of Cross-cultural Gerontology 13(4), 333-359.

Van der Geest S (2002) The toilet: dignity, privacy and care of elderly people in Kwahu, Ghana. In Stroeken $\mathrm{K}$ and Makoni S (eds). Sociolinguistic and Anthropological Approaches to Ageing in Africa. New York: Routledge, pp. 227-244.

Vaughan L, Leng X, La Monte MJ, Tindle HA, Cochrane BB and Shumaker SA (2016) Functional independence in late-life: maintaining physical functioning in older adulthood predicts daily life function after age 80. Journals of Gerontology: Biomedical Sciences and Medical Sciences 71A, S79-S86.

Wa Municipal Assembly (2011) Annual Report of the Wa Municipal Assembly 2010. Available at https:// www.google.com/url? sa=t\&rct=j\&q=\&esrc=s\&source=web\&cd=\&cad=rja\&uact=8\&ved=2ahUKEwj-hPm jg9jvAhWKFLcAHaG8DRkQFjAAegQIAhAD\&url=https\%3A\%2F\%2Fwww2.statsghana.gov.gh\%2Fdocfiles \%2F2010_District_Report\%2FUpper\%2520West\%2FWA\%2520MUNICIPAL.pdf\&usg=AOvVaw3qn4VYS vxNsIc6qGQlhX5t.

World Health Organization (WHO) (2001) International Classification of Functioning, Disability and Health: ICF. Geneva: WHO.

World Health Organization (WHO) (2002) Towards a Common Language for Functioning, Disability and Health: ICF. Geneva: WHO. Available at www.who.int/icf/beginners/bg.pdf.

World Health Organization (WHO) (2014) Ghana Country Assessment Report on Ageing and Health. Geneva: WHO. Available at http://apps.who.int/iris/bitstream/10665/126341/1/9789241507332_eng.pdf.

World Health Organization (WHO) (2015) World Report on Ageing and Health. Geneva: WHO.

Wu LW, Chen WL, Peng TC, Chiang ST, Yang HF, Sun YS, Chan JY and Kao TW (2016) All-cause mortality risk in elderly individuals with disabilities: a retrospective observational study. BMJ Open 6(9).

Yeung J, Jones A, Jhangri GS, Gibson W, Hunter KF and Wagg A (2019) Toileting disability in older people residing in long-term care or assisted living facilities: a scoping review of the literature. Journal of Wound Ostomy \& Continence Nursing 46, 424-433.

Yu HW, Chen DR, Chiang TL, Tu YK and Chen YM (2015) Disability trajectories and associated disablement process factors among older adults in Taiwan. Archives of Gerontology and Geriatrics 60, 272-280.

Cite this article: Awuviry-Newton K, Wales K, Tavener M, Kowal P, Byles J (2023). Functional difficulties and toileting among older adults in Ghana: evidence from the World Health Organization Study on global AGEing and adult health (SAGE) Ghana Wave 1. Ageing \& Society 43, 53-75. https://doi.org/10.1017/ S0144686X21000453 